\title{
The Right Person for the Right Job: a Study on the Need for Enhancing Collaboration between Shipping Companies \& Maritime Academies
}

\author{
James G. Davy*, Chang-Kyun Noh** \\ * Graduate Student, Division of Marine Transportation, Mokpo Maritime University, Mokpo \\ ** Associate Professor, Division of Marine Transportation, Mokpo
}

\begin{abstract}
Working onboard large ocean-going vessels is one of many industries that is by its very nature extremely error-provoking. In industries such as aviation, nuclear power, healthcare and transport, the need for mental preparedness and professionalism are amongst the qualities essential for the management of complex hazardous systems. Recruiting, training, and more importantly retaining the right people to work in these industries is of paramount importance if safety is to be continuously improved and economic benefits realized.Through consideration of extant empirical literature this paper will explore the need for enhancing collaboration between shipping companies and maritime training insitutes in order to provide the industry with those most capable for the job. It will be concluded that by providing a strong maritime foundation from the outset of training, maritime academies in South Korea can provide shipping companies with a wealth of highly qualified, motivated officers who will contribute to safety and remain valuable assets within the industry for years to come.
\end{abstract}

Key words : Collaboration, Recruitment, Training, Retention, Safety, Qualified.

\section{Introduction}

The training, recruiting, and retention of the best people for the position of maritime officer is not an easy task. On succesful completion of a maritime education program, it is paramount that sufficient attention be paid to ensuring that cadets are fully qualified and ready to provide shipping companies with the skills needed to operate their vessels. This paper deals with three areas of the maritime industry that are continually discussed at conferences and forums around the globe: the lack of seafarers, improvement of safety and the need for highly qualified crew. It will be shown that by improved collaboration between shipping companies and maritime training facilities many of the problems could be significantly reduced.

The maritime industry is experiencing a continuing lack of qualified seafarers. This has resulted in an aging workforce and the need to hire temporary, often foreign crew whose training of lack thereof may contribute to safety problems. Despite efforts at improving safety there continues to be weaknesses in the various safety systems or defences that have been put in place. These weaknesses result in incidents, accidents or catastrophes of varying degree. By improving collaboration between shipping companies and maritime institutes the most effective ways of training and education can be found. International governing bodies such as the International Maritime Organization (IMO) are continuously setting standards for training of seafarers. However, crew on board often fail to act in safe ways because they do not have the appropriate skills. It will be shown that from improved collaboration between shipping companies and maritime institutes, there can be concensus on the skills that need to be acquired and developed prior to recruitment.

\section{Literature Review}

\subsection{Officer Shortages}

The need for qualified officers to operate ocean-going vessels has been a topical issue within maritime organizations over the last two decades. With growing economies in Asia, predictions about the need for more officers and ratings have been a major concern for all shipping companies. According to the European Commission in 2001, in a paper on Maritime Safety, the declining number of well-qualified EU seafarers was recognised as a problem, particularly in terms of the loss of knowledge to the maritime industry as a whole (European Commission, 2001).

\footnotetext{
* james@mmu.ac.kr 061)240-7172

** cknoh@mmu.ac.kr 061)240-7172
} 
This is supported by research published by the Baltic International Maritime Council (BIMCO) and International Shipping Federation (ISF) in their study on the demand and supply of seafarers. They stated in 2005 that there was a shortage of 10,000 officer's worldwide and that by 2015 this may reach 27,000 (BIMCO/ISF 2005). Table 1 gives the figures from the 2005 Manpower Update and shows the lack of officers at that time. ISF members commented that lack of interest in a career at sea is one of the many challenges that shipping faces. They believe one of the main reasons for the lack of seafarers is the poor image that a career at sea has with most young people (BIMCO/ISF, 2005). Piracy continues to be common news in the media and the report of the UN Secretary General's Special Adviser on Piracy, Jack Lang, on 25 January 2011 indicated that 1900 people had been taken hostage since 2008 (EUNAVFOR, 2011).

Table 1 Figures showing officer and rating supply and demand

\begin{tabular}{|l|l|l|l|}
\hline & SUPPLY & DEMAND & BALANCE \\
\hline OFFICERS & 466,000 & 476,000 & $-10,000$ \\
\hline RATINGS & 721,000 & 586,000 & 135,000 \\
\hline
\end{tabular}

Source: BIMCO/ISF 2005

As Dr S. Cahoon of the Australian Maritime College points out, a job at sea is often characterised by boredom, isolation and unacceptable working conditions (Cahoon, 2011). In an age when instant contact with friends and family is the expected norm and when reliance on SMS communication and social networking is taken for granted, life on board can often be very stressful. Dr Cahoon notes that unlike previous generations, the present generation are more prone to 'job promiscuity' and are unlikely to stay with a company or even an industry if their expectations and needs are not satisfactorily met. Job satisfaction, therefore, is essential if companies are to retain the staff they have trained and invested in (BIMCO/ISF 2005). Investigating reasons for a decrease of interest in a maritime career was the purpose of the setting up of the Task Force of Maritime Employment and Competitiveness (TFMEC) by the European Commision in 2011. Recognizing obstacles both to entry to the maritime profession by European youngsters and their recruitment by European employers, the Task Force stated the need for action to improve seafaring's image and focus on taking concrete action to guarantee and improve the quality of life at sea and seafarers'career (TFMEC, 2011).

After the start of the global economic downturn in 2008, workforce demands naturally decreased and therefore the earlier predictions were not as severe as first thought. Professor R. Wilson was quoted by Andrew Linington of Nautilus as saying that, "if we had not had the crisis, the industry would now be in a far more difficult position" (Nautilus, 2011). Another reason for an overall picture of equilibrium of manpower since 2008 is the increase of people entering the workforce from emerging economies such as China, India and the Philippines. This has offset the previous shortages somewhat, creating a more positive view of the current manning levels. This is shown in Table 2 under the heading Far East.

Table 2. Global Seafarer Supply by Broad Geographical Area

\begin{tabular}{|l|c|c|c|c|}
\hline Area & \multicolumn{4}{|c|}{ Current supply } \\
\hline & $\begin{array}{c}\text { Officers } \\
(1000 \text { 's })\end{array}$ & $\%$ & $\begin{array}{c}\text { Ratings } \\
(1000 ' s)\end{array}$ & $\%$ \\
\hline OECD Countries & 184 & 29.4 & 143 & 19.2 \\
\hline Eastern Europe & 127 & 20.3 & 109 & 14.6 \\
\hline Africa / Latin America & 50 & 8.0 & 112 & 15.0 \\
\hline Far East & 184 & 29.5 & 275 & 36.7 \\
\hline Indian Sub-Continent & 80 & 12.8 & 108 & 14.5 \\
\hline All National Groups & 624 & 100.0 & 747 & 100.0 \\
\hline
\end{tabular}

Source: BIMCO/ISF Manpower 2010 Update

The current supply shown in Table 2 is based on the number of seafarers holding STCW certificates which is estimated to be 624,000 officers and 747,000 ratings. The demand estimates of Table 1 were based on the number, size and type of ships in the world fleet and the necessary manning levels required. Although the present figures seem to show a balance just short or $2 \%, \mathrm{BIMCO}$ and ISF are quick to point out that if the shipping industry recovers from the economic downturn and experiences similar growth as before then there could be serious trouble (BIMCO, 2010). From the Manpower 2010 update it was noted that the industry constantly requires well qualified and high calibre seafarers capable of adapting to change and handling the wide range of tasks required of them (BIMCO, 2010). Furthermore, BIMCO and ISF went on to say that any training program provided must ensure that quality is not compromised in the quest for increasing 
quantity. In their Interim Report of 2005, one key concern mentioned was that of the high turnover of employees within the industry and an insufficient number of applicants of the required quality (BIMCO, 2005). The need to recruit higher quality trainees was also noted by the International Labour Office (ILO) in their 2006 report. They noted a growing shortage of people competent to undertake higher level responsibilities on board and ashore and the increasing difficulty in recruiting suitable people, particularly to serve as seagoing officers (ILO, 2006). A study carried out by the International Maritime Employers Committee (IMEC) describes the situation as 'acute and escalating'. They pointed out that inadequate training standards in some areas - 'notably but not exclusively the Philippines' mean that barely $20 \%$ of each year's cadet intake attains both officer qualifications and an officer's job within four years (IMEC, 2007).

\subsection{Improving Safety}

Safety at sea continues to be one of the most salient issues in maritime discussions. Despite new aids to assist bridge navigators, major navigational accidents continue to occur (Spencer, 2009; IMO, 2002a; Hetherington et.al, 2006). One of the key points made by BIMCO and ISF concerning safety was that improved training and recruitment levels need to be maintained to ensure a pool of suitably qualified and high calibre seafarers (BIMCO, 2010). It is important to understand that for individuals and teams to perform effectively in high-risk enviroments, they must be proficient in non-technical skills and this must start at the educational level (Flin, O'Connor, Crichton, 2008). In expounding the importance of English as a common language for the social harmony of crew members, Short (2006) emphasized the need for good communication for teamwork that would be vital in emergency situations. She stated that "during trainees' early training at shore based establishments it is important to raise awareness" (Short, 2006). This was supported by the research of Hetherington et.al in their article on the human element in shipping safety (Hetherington et.al, 2006). Although it is well known amongst maritime educators and shipping companies the type of practical skills needed, it is not so clearly understood that there are also non-technical skills that are essential if a crew is to successfully work together on board a vessel (Flin, O'Connor, Crichton, 2008). Examples of non-technical skills recommended by the ILO and researched by Flin include leadership skills, communication, situational awareness, and motivation (ILO 2006).

\subsection{Providing Qualified Seafarers}

Supplying qualified, high calibre seafarers to the industry is essential and each crew member must be capable from the start of his/her career. Mistakes have become less acceptable and often the consequences are more serious. After reviewing five case studies of maritime accidents and incidents, Gatfield, Pekcan and Barnett, revealed that poor team performance leading to lack of situational awareness and poor decision making is the cause of many accidents. They also found that cultural issues (national and organizational and professional) are often the root causes of poor team performance through violation of procedures, lack of communication and system understanding between team members (Gatfield et. al., 2006). This was supported by a review of the accident databases from the USA, UK, Canada, Australia and Norway that confirms human error to be the dominant factor in maritime accidents (Baker, 2005). The following conclusions were drawn:

- Although the total number of accidents is declining, human error continues to be a dominant factor in 80 $85 \%$ of maritime accidents.

- Failures of situational awareness and situation assessment overwhelmingly dominate.

- Human fatigue and task omission seem closely related to failures of situational awareness.

Gatfield et al. concluded from their study that it is important through training programs to detect behaviours that are detrimental to the teams overall performance and that after detection, through a process of debriefing alongside simulation training, it is essential that behaviour be changed at the cognitive level (Gatfield et. al., 2006). The traditional type of lecture with no consideration to the wider set of skills needed is unacceptable for young cadets who will shoulder the heavy responsibilities that come from life onboard. The European Commission recognised this in their paper on Maritime Safety, noting that incidents and accidents related to communication problems in open seas or under pilotage indicate the need to consider language and cultural issues in the recruitment and training of ship crews (European Commission, 2001). Learning a wide skill set will eventually allow the seafarer to have more job appeal if an onshore position is eventually sought. Mark Charman notes that companies are looking for people with more than just technical experience. People who have the ability to adapt, be articulate and work well as part of a team are the ones 
most companies hire (Charman, 2011).

\section{Proposals for Progress}

The three areas mentioned above are the subject of this section. Each area that is considered needs to be viewed in the light of the entire maritime system since there is no part that operates in isolation. It is through the combined improvement of the various inter-depentant systems that improvement can be continuous and economic success attained.

\subsection{Officer Shortages}

- Improve shipping image \& job satisfaction

- Increase officer retention \& reduce employee turnover

- Focus on quality not quantity

The shortage of crew is a global concern and all sectors of the industry need to work together in pursuit of best practice. The author believes that maritime educational facilities are in a most excellent position to work alongside shipping companies in providing a sustainable source of manpower that is well-qualified and likely to remain in the industry for years to come.

The image of a career at sea remains unattractive and therefore retaining crew is very difficult. Land-based jobs are highly sought after by the younger generation leaving a much older onboard crew at the 'sharp-end' who are themselves ready for retirement. There has been a growing need to hire more foreign crew who are often ill-qualified or whose training and background is not easily confirmable. Although foreign crew are often a cheaper source of labour for shipping companies they often prefer short-term contracts and are reluctant to progress to greater responsibility. The training and experiences learnt during a period at sea is also very much wasted if retention of seafarers is not maintained by the company itself and even worse if the employee moves into a different industry all together. It is only through years of experience that many of the exacting skills needed for such a responsible job can be fine tuned and used to avert some of the very real dangers that often arise at sea.

By improving collaboration shipping companies and maritime training facilities can work at improving the image of a job at sea. After the industry has more clearly defined its needs regarding the type of person most suitable for a seafaring position, shipping companies can make those pre-requisites known to the labour pool, namely the training academies. Ensuring that the training curriculum is relevant and covers more than just technical knowledge (See Section 3.3) will allow young officers to realize their full potential when onboard. Developing a new generation of quality officers that are highly valued by the industry will result in greater job satisfaction and employee retention.

\subsection{Improving Safety}

- Improve training

- Focus on non-technical skills

- Develop error / accident wisdom

- Develop a safety culture

Through improved collaboration between shipping companies and maritime educational facilities, a foundation of true safety culture can be achieved. James Reason, British psychologist and creator of the Swiss Cheese Model, notes that each commercial organization has two imperatives: to keep its risks as low as possible and still stay in business (Reason, 2008). He refers to this balance as the companies 'optimal operating zone'. In the maritime industry where a simple mistake can cause huge financial and environmental damage, maintaining the balance between protection of the shipping environment and production in terms of profit is a tricky business. Understanding the work of Reason may prove invaluable in the development of safety education.

Figure 1 below shows the importance of balance using the Knotted Rubber Band Model. The middle section of the model is the optimal operating zone and on either side there are protective and productive resources. The black strips are the rubber bands that represent limited resources.

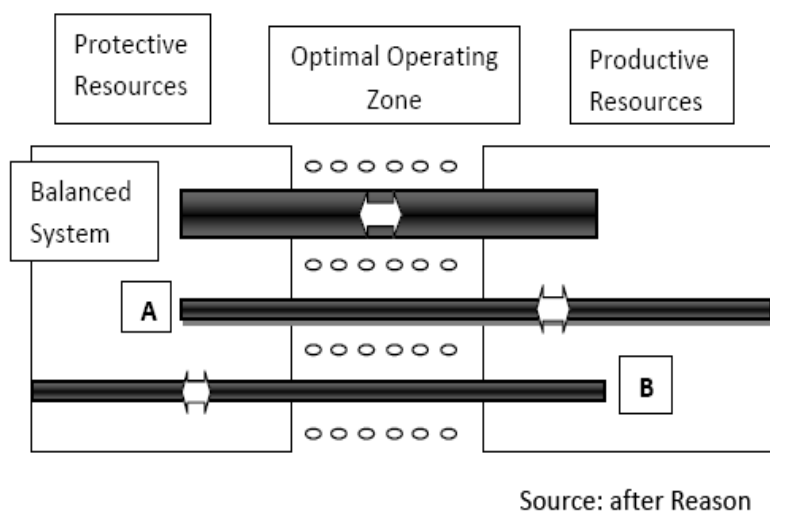

Fig. 1 Showing the resource implications of the knotted rubber band model.

There are three configurations shown in Figure 1. The 
top shows a balanced state in which the $\mathrm{knot}^{1)}$ is centrally positioned with considerable potential for corrective action. Configuration A shows an unbalanced state whereby the focus on production has pulled the knot out of the optimal zone. This could result in weakening the safety defences that should prevent incidents and accidents occurring. Similarly, configuration B is also out of balance but in the opposite direction. In this case, safety and protection has become a burden due to too many rules, regulations, paperwork, etc.

The model in Figure 1 demonstrates that the creation of resilient safety systems that continue to operate at optimal levels is essential if a company is to survive and prosper. Since it is the people at the 'sharp-end' of the shipping industry that are directly responsible for shipping operations, they need to have the full support and adequate training to be able to perform their tasks successfully. The importance of being able to recruit the most suitable people for the job cannot be under-estimated. Reason points out that in high-technology activities such as transport, the dangers are potentially great and far-reaching even though the frequency of adverse events is generally low (Reason, 2008). Having the right people for the job from the outset is, therefore, essential to the safety of the crew, ship and environment.

Motivation is a very important aspect of a persons' personality that will have a direct impact on the way they approach their job. There are often three reasons why students choose to apply for a cadet course at a maritime university in South Korea:

a. Better job opportunities after graduation

b. Alternative to military service

c. Financially attractive

Given the increase in unemployment in South Korea and the huge number of graduates applying for jobs in the cities, the ease at which employment can be attained in the shipping industry is very attractive with nearly 100\% of students being hired directly after graduation. The compulsory military training that all Korean males are required to complete is roughly two years in length. During this time there is no opportunity to develop industry specific skills, earn significant money, and the obvious negatives such as isolation from family, friends and other inherent dangers. Refusal of duty is a human right that is still violated by the government of South Korea and this continues to motivate a constant stream of young people to apply to maritime schools.

It is often the case that young people are willing to choose an occupation that is perhaps not ideal for them to avoid military service. The financial motivation is also attractive so that a young Korean can accomplish his culturally expected lifestyle of getting married with two children, a house and nice car, and a 'stable' shore-based job by age of about thirty. An on board job after graduation allows this to happen relatively easily. It is clear, however, that having such motivational factors as those mentioned is not conducive to creating people that have a love for what they do. ${ }^{2)}$ As was discussed in Section 2.2, teamwork and having a positive attitude to being at sea is essential if safety is to be maintained and employees retained. With the isolation, job related stress and high levels of fatigue so often associated with being onboard, it is essential that the right people for the job are attracted into the industry. If not, complacency, omissions, and overt risk-taking could easily result.

Having a understanding of accident causation such as Reasons' Swiss Cheese Model as shown in Figure 2 would help cadets, their educators and shipping companies to realize that hiring the right people for the job is essential to safety in general and for the overall effectiveness of operations.

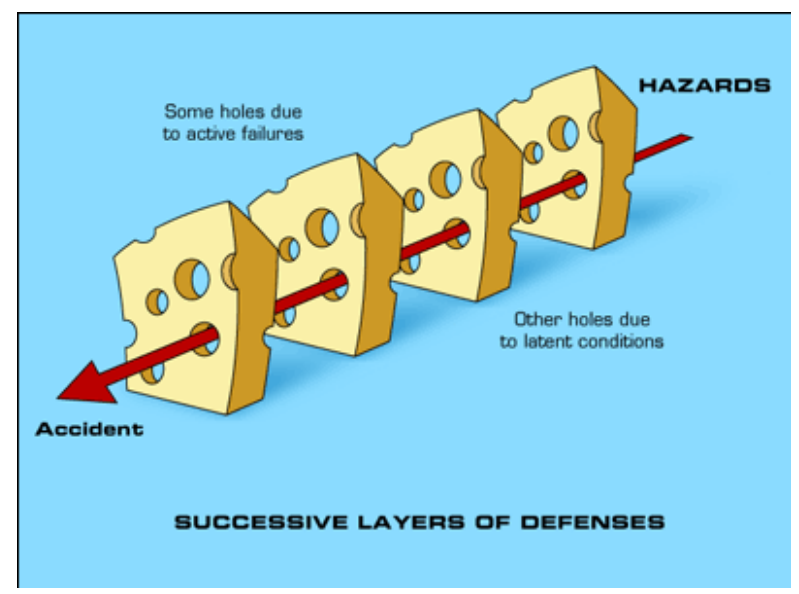

Fig. 2 Swiss Cheese Model of Accident Causation Source: after Reason 2008

\footnotetext{
1) The knot is indicated by an arrow

2) See "Waves of Passion - a film on careers as an officer in the merchant navy", http://ec.europa.eu/dgs/energy_transport/videos/transport/2004_02_ wave_of_passion_en.htm
} 
Each slice represents a defensive layer in the process involved. The holes represent opportunities for failure of process. An error may allow a problem to pass through a hole in one layer, but in the next layer the holes are in different places, and the problem should be caught. Each layer is a defence against potential error impacting the outcome. For a catastrophic error to occur, the holes need to align. If the layers are set up with all the holes lined up, this is an inherently flawed system that will allow a problem at the beginning to progress all the way through to adversely affect the outcome. Each slice of cheese is an opportunity to stop an error. The more defences there are the better. Also the fewer the holes and the smaller the holes, the more likely it will be to stop errors that may occur (Reason, 2008).

As regards shipping, the last layer of defence is the seafarer operating the ship. If there are weaknesses in this human layer then it is very likely that an error will eventually occur. Providing the correct support and training for those working at the sharp-end of the industry can help them to become error wise and vigilant to the realities of human error. By hiring the right people for the job, shipping companies can ensure the safety of their ships, crews and profits. During recruitment, shipping companies should have a clear idea of the type of people they are hiring including their future goals and aspirations within the industry and company.

\subsection{Providing Qualified Seafarers}

- Focus on non-technical skills

- Develop safety culture

- Improve communication skills

- Remove unnecessary curriculum

In a fast changing industry environment it is important to continually ask 'what contributes to being qualified for a job at sea?' As we have noted, training must go beyond having the practical skills needed to operate a ship. By improving collaboration between maritime schools and shipping companies, the needs of the industry can be established in terms of the non-technical skills that need to be developed. It is the training of such human skills that will prove most beneficial to a company in the long-term as well as allow for the retention of seafarers and enable employees to develop their career within the industry. As was noted in Section 2.3, the range of skills that are necessary for a qualified seafarer are many and varied. Of course, shipping companies themselves need to have a clear understanding of the skills needed from their new recruits by receiving continuous input from experienced seafarers that are currently at sea. When this has been thoroughly achieved, company representatives can approach maritime educators to find the best practice to developing a curriculum that will produce the competencies required.

It has become apparent that some of the content that is taught at some maritime institutes may be of little practical use while on board. An example of inappropriate or unrelated course content is in the use of the Test of English for International Communication (TOEIC). This test which is used extensively in South Korea for university entrance, graduation and recruitment continues to exert a very negative influence on the Korean education system in general and especially on the maritime training curriculum. Empirical research carried out in 2010 proved beyond doubt that including the TOEIC within a maritime curriculum or recruitment process does in fact hinder the cadet from essential maritime training. ${ }^{3)}$

To highlight this we can briefly review some of the data that was published (Davy, Noh, 2010). Empirical data that was collected from over two hundred cadets that had received over six months onboard training with shipping companies and over three years of education at one maritime training facility ${ }^{4}$, were asked about the relevance of this high-stakes test. The participants were given the following sentence and asked to agree or disagree with it: the TOEIC lessons I took while at university were very helpful for my on board life. Only 8.5\% of students responded that they "agreed" or "strongly agreed" that the TOEIC was very helpful for on board life. However, 22\% "neither agreed nor disagreed" and 33\% "disagreed". 34.4\% "strongly disagreed". These results can be seen in Figure 3. Considering the amount of time that is spent on the test and the importance it has as a high stakes test for cadets it would presumably be the view of the training institute and shipping companies that the TOEIC had some intrinsic value to the training of seafarers. However, as can be seen from the responses of these new officers it can be confidently stated that they believe the TOEIC is NOT useful for their on board life.

3) See paper entitled “A Comparative Review between the language programs of Maritime Institutes in Korea and Europe”, Davy \& Noh 2011, Journal of Navigation and ort Research Vol.35, No.9, 31 December 2011.

4) Mokpo National Maritime University 


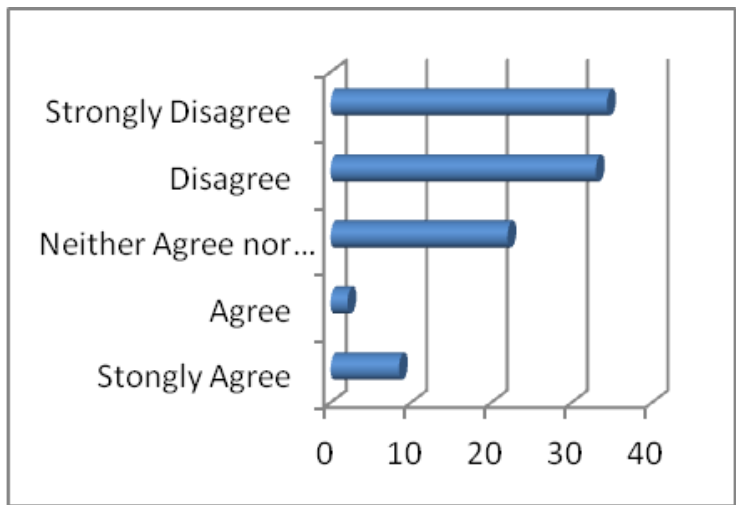

Fig. 3 Frequency Statistics for Officers

To understand how new officers at sea dealt with the on board environment the previously mentioned research (Davy, Noh, 2010) asked respondents to agree or disagree with the following statement: I adapted easily to life on board. 22.3\% "strongly agreed" that they did easily adapt along with $27.7 \%$ who also "agreed". $26.8 \%$ were unsure whether they agreed or disagreed. The number of respondents that "disagreed" was 12.5\% and 5.3\% "strongly disagreed". The mean of the responses is shown in Table 3. As the $\mathrm{P}-$ Value for this item was $>0.05$ a One-Sample T-Test was carried out as detailed below in Table 4 .

Table 3 One-Sample Statistics

\begin{tabular}{|c|c|c|c|c|}
\hline & $\mathrm{N}$ & Mean & Std. Deviation & Std. Error Mean \\
\hline Item & 210 & 3.42 & 1.296 & .089 \\
\hline
\end{tabular}

Table 4 One-Sample Test

\begin{tabular}{|c|c|c|c|c|c|c|}
\hline & \multicolumn{6}{|c|}{ Test Value $=4$} \\
\hline & \multirow[t]{2}{*}{$\mathrm{t}$} & \multirow[t]{2}{*}{ df } & \multirow[t]{2}{*}{$\begin{array}{c}\text { Sig. } \\
\text { (2-tailed) }\end{array}$} & \multirow[t]{2}{*}{$\begin{array}{c}\text { Mean } \\
\text { Difference }\end{array}$} & \multicolumn{2}{|c|}{$\begin{array}{l}95 \% \text { Confidence } \\
\text { Interval of the } \\
\text { Difference }\end{array}$} \\
\hline & & & & & Lower & Upper \\
\hline Item & -6.495 & 209 & .000 & -.581 & -.76 & -.40 \\
\hline
\end{tabular}

This question was used to investigate how easy cadets were able to adapt to life on board. Although there was not a majority who had difficulty adapting, the figures show that a quarter of students neither agreed nor disagreed This suggests that these cadets had some difficulties and that more could be done to prepare them. Almost a fifth of respondents stated that they did not adapt easily to life at sea and this figure further suggests that more training time could be spent in environmental training and industry specific learning such as situational awareness and safety.

The above date was further supported by the respondents when asked to agree or disagree with the following statement: I was able to easily resolve any personal conflicts or misunderstandings with other crew members despite rank, nationality or other differences. 34.8\% "neither agreed nor disagreed" with this statement. In total $31.2 \%$ "disagreed" and $30.3 \%$ "agreed" that they were able to easily resolve personal conflicts or misunderstandings despite rank or nationality. These figures indicate that the cadets were not able to easily resolve conflicts or misunderstandings with other crew members despite nationality or rank. A third of the population felt that solving conflicts on board was not easy and therefore making time for specific and non-technical, industry relevant training would prove to be a wise long-term investment. Course content, instruction method and learning outcomes would be greatly enhanced by the full collaboration of shipping companies and maritime institutes.

\section{Conclusion}

This paper has considered three areas of the maritime industry that need continual improvement: (1) the lack of officers, (2) safety, and (3) the need for highly qualified workers. Although these issues have been discussed seperately they are profoundly related to each other and it is clear that taking a holistic approach to improvement is best practice. It is hoped that consideration of these issues will prompt further research and investigation into developing the concepts discussed.

It has been argued that by improving collaboration between the maritime training institute and shipping companies, the needs of the industry can be more successfully met and solutions developed synergistically. For each of the three problems proposals have been made that will ensure continuous improvement occurs: (1) to solve the shortage of officers the industry as a whole needs to look at ways of improving the image of a career at sea in order to retain workers. High employee turn-over must be discouraged and focus must be on quality rather than quality; (2) to improve safety, collaboration between shipping companies and training institutes on the needs of the industry and ways to implement effective training must be considered. Focus on the non-technical skills essential for maritime officer's needs attention. Developing a safety culture within the educational setting to create a solid foundation of safety and error wisdon is also needed; (3) and finally, in order to provide the industry with the 
highest calibre seafarers possible, attention needs to be given to how non-technical skills are taught, evaluated and maintained. Helping workers who operate at the sharp end of the industry to develop a safety mindset prior to boarding is essential. The importance of improving communication skills needs to be highlighted and the curriculum of training academies needs constant evaluation in order ensure that it is applicable and effective in yeilding the best possible seafarers.

By working together more interdependently each organization can support the other in the common pursuit of developing excellent seafarers. By formulating clear definitions of the essential skills required of onboard crew, training academies would be able to develop curricula that is focus and applicable and shipping companies would be able to employ those most suitable. This would improve safety in the short-term and if retention of employees were maintained, would prove to be economically sound in the long-term. Many of the issues facing the maritime industry could successfully be tackled during cadet training before entering shipping companies. By creating training programs that are focused and based on the wide scope of skills needed for life at sea, a strong foundation of highly qualified, safety conscious officers would ensure the successful operation of ships and the future prosperity of shipping companies.

\section{References}

[1] Baker, C.C.(2005), "Accident database review of human element concerns: What do the results mean for classifiction?" Proc. Int Conf. Human Factors in Ship Design and Operation.

[2] Cahoon, S.(2011), "Shipping, Shortages and Generation Y”, Department of maritime and logistics management, Australian maritime college.

[3] Charman, M.(2011), Nautilus Telegraph, "Getting from sea to shore". January edition, Vol. 44 Number 1, p.19

[4] Davy, J.(2011), “A study on the Importance of English Education within Maritime Safety", Master thesis submitted 2011, Mokpo Maritime University.

[5] EUNAVFOR(2011), "The Fear of Piracy”, Report of the Task Force on Maritime Employment and Competitiveness p. 10 See http://www.eunavfor.eu/

[6] European Commision.(2001), "Maritime Safety Results from the Transport Research Programme", p.11. Retrieved from http://www.transport-research.info/ Upload/Documents/200406/20040617_110936_15842_marit ime_safety.pdf

[7] Flin, R., O'Connor, P., Crichton, M.(2008), "Safety at the Sharp End", pp.243-261, Ashgate.

[8] Gatfield, Pekcan and Barnett.(2006), "The Janus principle in Maritime Safety: Looking Backwards to Look Forward", Warsash Maritime Centre, UK.

[9] Hetherington, C., Flin, R., Mearns, K.(2006), "Safety in Shipping: the human element", Journal of Safety Research 37 (2006) 401-411.

[10] IMEC(2007), "Global Shortage is Starting to Bite", Nautilus UK Telgraph, September 2007, pp.22-23.

[11] International Labour Office(2006), "Report of the Director-General on Developments in the Maritime Sector", Report 2, International Labour Conference, $94^{\text {th }}$ session, 2006, Geneva.

[12] International Maritime Organisation (IMO)(2002), "Introduction to IMO"

[13] Nautilus Telegraph(2011), "New Alert on Officer Shortages", Vol. 44 Number 1, p.1.The Baltic International Maritime Council (BIMCO) and International Shipping Federation (ISF).(2010), "Manpower 2010 Update", pp.1-3.

[14] Reason, J.(2008), "The Human Contribution, Unsafe acts, accidents and heroic recoveries", Ashgate publishing, pp.265-288

[15] Short, V.A.(2006), "Maritime English Valuing a Common Language", Nautical Briefing, Supplement to Seaways, The Journal of the Nautical Insititute, p.2.

[16] Spencer, C.(2009), "Standard Safety" The Standard Special Edition 2009, retrieved from www.standardclub.com

[17] TFMEC(2011), "Report of the Task Force on Maritime Employment and Competitiveness and Policy Recommendations to the European Commission", Retrieved from http://ec.europa.eu/transport/maritime/ seafarers/doc/2011-06-09-tfmec.pdf

[18] The Baltic International Maritime Council (BIMCO) Interim Survey.(2005), "Interim Manpower survey", pp. $1-4$.

Received 7 May 2012

Revised 28 June 2012

Accepted 28 June 2012 